\section{Gender and left ventricular structural and functional differences in pulmonary hypertension among end stage renal disease patients on maintenance hemodialysis}

\author{
Daniel B Levin, Umar Malik, Ihab Ajaaj, Jon P Blaschke, Betty \\ Skipper, Sandra L McClelland, Kathleen Fagan, Antonia M \\ Harford, Philip G Zager and Veena Raizada*
}

Department of Internal Medicine, University of New Mexico, Albuquerque, NM, 87131-0001, USA

\section{Abstract}

Introduction: Pulmonary hypertension (PH) is prevalent in hemodialysis (HD). In the general population, more women than men have $\mathrm{PH}$ due to left ventricular (LV) disease with preserved ejection fraction (EF). Little is known about the gender-specific prevalence of $\mathrm{PH}$ and associated LV abnormalities in patients with end stage renal disease (ESRD) on HD. Our aim was to evaluate gender differences and LV structural and functional changes in PH among ESRD patients on HD.

Methods: Ninety-four patients (ages 23-77 years) underwent echocardiography after HD. Patients were divided based on estimated pulmonary artery systolic pressure (PASP) (Group A PASP $<40 \mathrm{~mm} \mathrm{Hg}$, Group B PASP $\geq 40 \mathrm{~mm} \mathrm{Hg}$ ). LV measurements included LV mass, LV internal dimensions, and LV ejection fraction (EF). LV diastolic function (LVDF) was assessed from mitral inflow deceleration time (DT) and E/A ratio.

Results: Fifty-five patients (59\%) had PH, including 32 of 49 men (65\%) and 23 of 45 women $(51 \%)$. LVEF was lower in Group B $(46.4 \pm 17.6$ vs. $62.4 \pm 14.4 \%, \mathrm{p}<0.001)$. Men with PH had higher LVIDd, cm (5.52 \pm 0.89 vs $4.78 \pm 0.75, p<0.001)$, LVIDs, cm (3.75 \pm 0.94 vs $3.14 \pm 0.91, p=0.03)$ LV mass, $g(236 \pm 74$ vs $189 \pm 56, p=0.02)$ and lower LVEF ( $40.0 \pm 16.7$ vs $52.0 \pm 15.6, p=0.008)$ than women.

Conclusion: Patients on HD have a high prevalence of PH. PH was not associated with clear LV structural changes. There was a depression in LV systolic function without changes in LVDF. PH patients were more often men with hypertrophied LV with depressed LV systolic function.

\section{More Information}

*Address for Correspondence: Veena Raizada Department of Internal Medicine, University of New Mexico, Albuquerque, NM, 87131-0001, USA, Tel: (505)272-4253; Fax (505)272-4356; Email: vraizada@salud.unm.edu

Submitted: 20 July 2019

Approved: 24 August 2019

Published: 26 August 2019

How to cite this article: DB Levin, Malik U, Ajaaj I, Blaschke JP, Skipper B, et al. Gender and left ventricular structural and functional differences in pulmonary hypertension among end stage renal disease patients on maintenance hemodialysis. J Clini Nephrol. 2019; 3: 154-160.

DOI: 10.29328/journal.jcn. 1001041

Copyright: (C) 2019 DB Levin, et al. This is an open access article distributed under the Creative Commons Attribution License, which permits unrestricted use, distribution, and reproduction in any medium, provided the original work is properly cited

Keywords: Pulmonary hypertension; End stage renal disease; Left ventricular dysfunction

Check for updates

\section{Introduction}

Pulmonary hypertension (PH) is a group of diseases characterized by elevated mean pulmonary artery pressure (> $20 \mathrm{~mm} \mathrm{Hg}$ ) at rest, measured invasively during right heart catheterization. $\mathrm{PH}$ may be due to derangements in pulmonary vascular resistance from a variety of causes, resulting in elevated pre-capillary pressures (pre-capillary $\mathrm{PH})$, or to left ventricular dysfunction, where increased left ventricular filling pressures are transmitted retrograde to the pulmonary capillary bed (post-capillary PH). PH is frequently found in patients with end stage renal disease (ESRD) on hemodialysis (HD). The pathogenesis of PH in ESRD is not completely known, but has been attributed to cardiovascular abnormalities, anemia, high cardiac output due to A-V fistula, hormonal and metabolic changes. Cardiovascular abnormalities include left ventricular (LV) hypertrophy, and systolic and diastolic dysfunction. PH due to left heart disease is classified in Group II of the World Health Organization (WHO) classification, and can be caused by elevation of pulmonary capillary pressure (PCP) alone or in combination with pulmonary arteriopathy [1]. PH included in Group II of the WHO is due to LV systolic and diastolic dysfunction due to valvular and non-valvular causes, and hypertrophic and dilated cardiomyopathies, both congenital and acquired. 
Left heart dysfunction has been recognized as the most common etiology of WHO Group II PH. Recently, heart failure (HF) due to left heart dysfunction has been classified as HF due to reduced ejection fraction (HFrEF, $\mathrm{EF} \leq 40 \%$ ) and $\mathrm{HF}$ due to preserved ejection fraction (HFpEF; $\mathrm{EF} \geq 50 \%$ ). Both types of $\mathrm{HF}$ are known to cause significant $\mathrm{PH}$ but recent studies in the general population have increasingly recognized $\mathrm{HFpEF}$ as the predominant cause of $\mathrm{PH}$ in both acute and chronic HF associated with left heart disease [2,3]. Accordingly, the 2009 WHO classification of PH recognizes $\mathrm{HFpEF}$ as the most frequent cause of $\mathrm{PH}$ due to left heart disease in the general population. However, it is not known whether patients with ESRD on HD with HFpEF have more severe PH than those with HFrEF. Specifically, WHO-II does not include patients with PH due to ESRD on HD, although, left heart abnormalities including impairment of LV function are common in these patients.

$\mathrm{PH}$ is strongly associated with diastolic dysfunction and has been increasingly recognized among ESRD patients on HD [4]. PH may contribute to limiting symptoms including dyspnea and is predictive of poor outcomes, including early graft dysfunction following renal transplantation [5]. Presence of pulmonary hypertension has also been shown to be an independent predictor of mortality in patients on hemodialysis [6]. Subclinical LV dysfunction is common in ESRD patients, with diastolic dysfunction being the hallmark functional abnormality [7]. 2-D echocardiography with Doppler is a validated tool for assessing parameters of diastolic filling [8]. Further, echocardiography is validated as a screening tool for assessing for $\mathrm{PH}$, though the cut off value of PASP $\geq 40 \mathrm{~mm} \mathrm{Hg}$ is only modest [9].

Though ESRD is strongly associated with structural changes and LV hypertrophy, depressed LV systolic function and $\mathrm{CHF}$, the relationship of these alterations in structure and function to $\mathrm{PH}$ is unclear. Despite evidence that some parameters of LV remodeling (LM mass index) may improve with initiation of HD, there remains concern that factors intrinsic to HD may be implicated in the pathogenesis of $\mathrm{PH}$ [10]. The relationship to systolic dysfunction is less clear, as most studies addressing PH in the ESRD population have excluded patients with LV systolic dysfunction. In some studies, PH appears to be related to time on HD and overall LF systolic function, though data have been inconsistent [11].

In the general population, more women than men have pulmonary hypertension (PH) due to left ventricular (LV) disease with preserved LV systolic function [12-14]. Little is known, however, about the gender-specific prevalence of $\mathrm{PH}$ and associated $\mathrm{LV}$ abnormalities in patients with end stage renal disease (ESRD) maintained on hemodialysis (HD). Studies in the United States HD population are limited. Further, there are significant variations in demographic trends with respect to utilization of HD for treatment of ESRD, worldwide, so the applicability of international studies to the domestic U.S. HD population is uncertain. Those published are relatively small, and use variable estimates of LV function (fractional shortening, estimated cardiac index), and did not consider parameters of diastolic function directly. Curiously, PH has been associated with greater midwall fractional shortening and better cardiac index, though increased left atrial diameter indexed to body surface area [15]. Other studies in the United States have demonstrated an inverse relationship between increasing TR jet velocity and LVEF, though patients with high TR velocity ( $\geq 3 \mathrm{~m} / \mathrm{s}$ ) demonstrated preserved EF of 53\%. These authors also observed a correlation between estimated PASP and PCWP, though it is not clear how PCWP was derived or estimated, and there were no other parameters of diastolic filing or LV filling pressure provided [16]. In addition, most studies evaluating PH in ESRD patients have excluded patients with coronary artery disease (CAD), wall motion abnormalities, and abnormal LV systolic function, with a few exceptions [16], and these abnormalities are common among patients with ESRD on HD.

Therefore, the aims of the present investigation were to examine in hemodialysis patients the severity of $\mathrm{PH}$ using American Society of Echocardiography (ASE) guidelines [17], left heart abnormalities including EF, and to identify the gender differences of $\mathrm{PH}$ and LV structure and function among male and female HD patients in a single-center, crosssectional study.

\section{Methods}

Prevalent HD patients $(n=94)$ were recruited from a facility operated by Dialysis Clinic Inc (DCI). Patients ranged in age from 22-77 years. Of the 94 patients enrolled, 45 were females and 49 were males. Inclusion criteria were limited to age $\geq 18 \mathrm{yrs}$, on maintenance HD, with agreement to participate in study. The study was approved by the University of New Mexico (UNM) Institutional Review Board and all subjects gave informed written consent prior to participating in the study. Patients were on HD from $<1$ to greater than 5 years.

At enrollment all patients underwent history and physical examination and baseline laboratory assessment. Those with significant valvular disease, LV wall motion abnormalities, and active ischemic heart disease with angina or recent revascularization were excluded. Upon completion of HD, patients were admitted to the Clinical Research Center at UNM and were placed on a renal-replacement, fluidrestricted diet. Baseline laboratories were obtained in the fasting state. Trans-thoracic 2-D echocardiography with Doppler (TTE) was completed 10-12 h after HD. Patients were evaluated per ASE guidelines: for LV dimensions, LV mass, relative wall thickness (RWT), LV systolic function (EF\%), LV diastolic function (E/A, DT), and left atrial (LA) size. Studies were completed by experienced sonographers, and 
were interpreted by two experienced echocardiographers. EF was assessed qualitatively. In cases where there was disagreement, prior EF assessments by alternate methods (nuclear ventriculography and nuclear stress-imaging) were considered. Pulmonary artery systolic pressure (PASP) was estimated from maximal tricuspid regurgitant (TR) jet velocity plus estimated right atrial pressure, derived from IVC dimensions, per current ASE guidelines. PH was considered present when estimated PASP was greater than or equal to $40 \mathrm{~mm} \mathrm{Hg}$, in an effort to avoid over-diagnosis. Patients were divided into two groups based on estimated PASP; Group A (PASP $<40 \mathrm{~mm} \mathrm{Hg}$ ) and Group B (PASP $\geq 40 \mathrm{~mm} \mathrm{Hg}$ ).

Wilcoxon rank sum test was used for comparing groups, and Fisher's exact test was used to calculate p-values for duration of HD and presence of $\mathrm{PH}$ with Mantzel-Hantszel test for trend utilized for relationship between time on HD and presence of HD. The Spearman correlation was used in evaluating the relationship between age and EF. Data are presented as mean $\pm \mathrm{SD}$, with $\mathrm{P}<0.05$ considered significant.

\section{Results}

Of the 94 patients, 39 (41\%) were classified into Group A (PASP $<40 \mathrm{~mm} \mathrm{Hg}$ ). Fifty-five patients (59\%) were classified into Group B (PASP $\geq 40 \mathrm{~mm} \mathrm{Hg}$ ), including 32 of 49 men $(65 \%)$ and 23 of 45 women (51\%). Systolic blood pressures did not differ between Group A (148 $\pm 25 \mathrm{~mm} \mathrm{Hg}$ ) and Group B (155 $\pm 29 \mathrm{~mm} \mathrm{Hg}), \mathrm{p}=0.3$ respectively. Diastolic blood pressures were also similar between Group A (84 $\pm 13 \mathrm{~mm}$ $\mathrm{Hg}$ ) and Group B (82 \pm 15 mm Hg), p = 0.38 (Table 1).

LVIDd ( $4.87 \pm 0.84$ vs. $5.21 \pm 0.88 \mathrm{~cm}, \mathrm{p}=0.05) ;$ LVIDs (3.07 \pm 0.76 vs. $3.45 \pm 0.96 \mathrm{~cm}, \mathrm{p}=0.05$ ); IVS and PW thicknesses $(1.09 \pm 0.19$ vs. $1.03 \pm 0.15 \mathrm{~cm}, \mathrm{p}=0.19$; and $1.12 \pm 0.17$ vs. $1.07 \pm 0.16 \mathrm{~cm}, \mathrm{p}=0.25$ ); and LV mass, (113 \pm 34 vs. 123 $\pm 38 \mathrm{~g} / \mathrm{m}^{2}, \mathrm{p}=0.12$ ) were all similar between Group A and $\mathrm{B}$, respectively. The LVEF was lower in Group B compared to Group A, respectively (46.4 \pm 17.6 vs. $62.4 \pm 14.4 \%$, p < $0.001)$. Both groups exhibited DTs of $>200 \mathrm{~ms}$ (257 \pm 52 vs. $215 \pm 47 \mathrm{~ms}, \mathrm{p}=0.006$ ), with no significant between-group difference in the E/A ratio (E/A $1.15 \pm 0.44$ vs. $1.48 \pm 0.74, p$ $=0.06$ ) (Figure 1 ).

Men with PH had significantly higher LVIDd, cm (5.52 \pm 0.89 vs $4.78 \pm 0.75, \mathrm{p}<0.001)$, LVIDs, $\mathrm{cm}(3.75 \pm 0.94$ vs $3.14 \pm 0.91, \mathrm{p}=0.03) \mathrm{LV}$ mass, $\mathrm{g}(236 \pm 74$ vs $189 \pm 56, \mathrm{p}=$ $0.02)$ and lower LVEF ( $40.0 \pm 16.7$ vs $52.0 \pm 15.6, p=0.008)$ than women with $\mathrm{PH}$. There were no differences in other parameters, including LV wall thickness, diastolic function parameters and blood pressure, between men and women with PH. All LV measurements were similar in men and women with PASP $<40 \mathrm{mmHg}$ (Figure 2).

\section{Discussion}

The present study highlights $\mathrm{PH}$ and LV abnormalities in

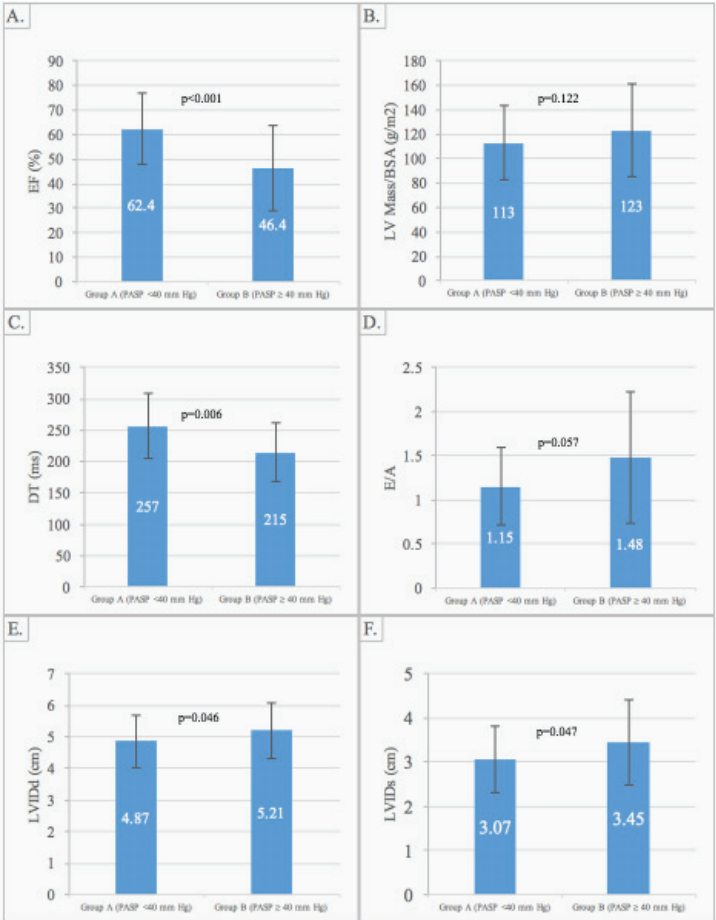

Figure 1: LV measurements in Group A (PASP $<40 \mathrm{~mm} \mathrm{Hg}$ ) vs. Group B (PASP $>40 \mathrm{~mm} \mathrm{Hg}$ ). Panel A demonstrates EF vs. PASP. Panel B demonstrates LV Mass/BSA vs. PASP. Panel C demonstrates DT vs. PASP. Panel D demonstrates E/A ratio vs. PASP. Panel E demonstrates LVIDd vs. PASP. Panel F demonstrates LVIDs vs. PASP. Abbreviations: PASP, pulmonary artery systolic pressure; EF, ejection fraction; LV, left ventricular; BSA, body surface area; DT, deceleration time; LVIDd, left ventricular internal diastolic dimensions; LVIDs, left ventricular internal systolic dimensions.

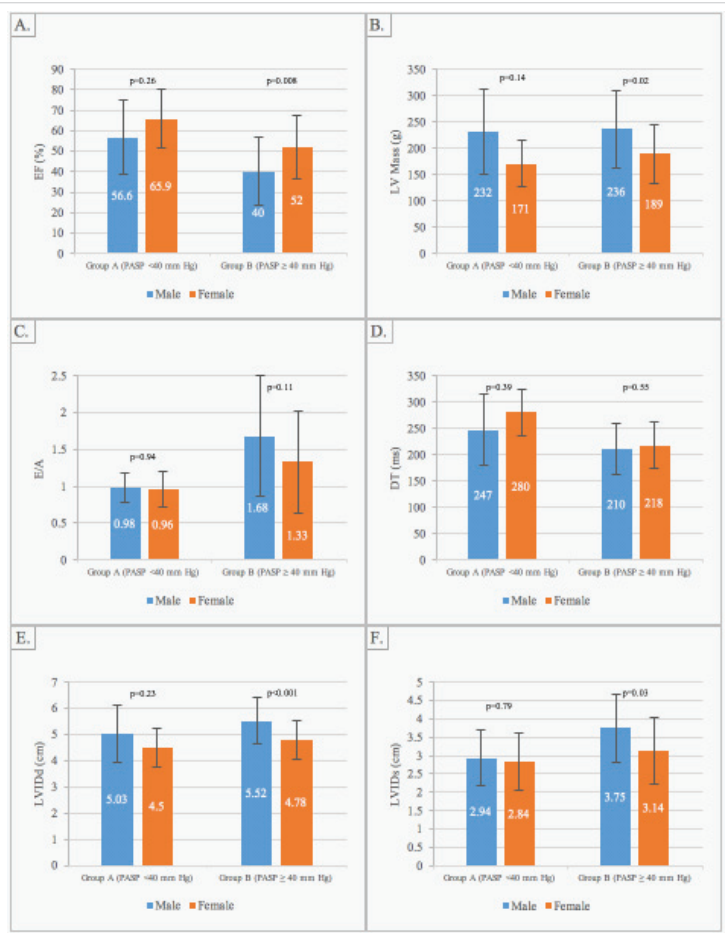

Figure 2: Gender differences in LV measurements in Group A (PASP $<40$ $\mathrm{mm} \mathrm{Hg}$ ) vs. Group B (PASP $>40 \mathrm{~mm} \mathrm{Hg}$ ). Panel A demonstrates EF vs. PASP. Panel B demonstrates LV Mass vs. PASP. Panel C demonstrates E/A vs. PASP. Panel D demonstrates DT ratio vs. PASP. Panel E demonstrates LVIDd vs. PASP. Panel F demonstrates LVIDs vs. PASP. Abbreviations: PASP, pulmonary artery systolic pressure; EF, ejection fraction; LV, left ventricular; DT, deceleration time; LVIDd, left ventricular internal diastolic dimensions; LVIDs, left ventricular internal systolic dimensions. 


\begin{tabular}{|c|c|c|c|}
\hline & $\begin{array}{c}\text { Group A (PASP }<40 \mathrm{~mm} \mathrm{Hg}) \\
(n=39)\end{array}$ & $\begin{array}{c}\text { Group B (PASP } \geq 40 \mathrm{~mm} \mathrm{Hg}) \\
(n=55)\end{array}$ & \\
\hline Variable & Mean \pm SD & Mean \pm SD & P-value \\
\hline Age & $48 \pm 13$ & $59 \pm 12$ & 0.001 \\
\hline Systolic BP & $148 \pm 25$ & $155 \pm 29$ & 0.30 \\
\hline BMI & $25.5 \pm 5.9$ & $26.2 \pm 7.7$ & 0.81 \\
\hline Hemoglobin & $12.8 \pm 1.5$ & $12.6 \pm 2.0$ & 0.88 \\
\hline
\end{tabular}

Abbreviations: PASP, pulmonary artery systolic pressure; BP, blood pressure; $\mathrm{BMI}$, body mass index $\left(\mathrm{kg} / \mathrm{m}^{2}\right)$

the majority of patients with ESRD on HD. LVEF was lower in patients with PASP $>40 \mathrm{~mm}$ Hg compared to those with PASP $<40 \mathrm{~mm}$ Hg. Unlike the general population, $\mathrm{PH}$ patients were more often men with enlarged and hypertrophied LV with depressed LV systolic function. Further studies are warranted to clarify the role of gender-specific LV abnormalities in the pathogenesis of $\mathrm{PH}$ among HD patients.

Our study showed that patients with LVEF $\leq 40 \%$ had more severe LV abnormalities and higher PA pressures compared to those with $\mathrm{EF} \geq 40 \%$. The HFrEF group had dilated LVs with increase in systolic and diastolic dimensions and severe LVH with severe PH. However, in patients with HFpEF, LV size was normal with borderline LVH and moderate PH. There was moderate (Grade II) diastolic dysfunction in both groups, which was somewhat more severe in the HFrEF group. Systolic blood pressure was borderline elevated with normal diastolic pressure in both groups.

Our study, similar to prior studies, found $\mathrm{PH}$ in the majority of patients with ESRD. The etiology for PH in ESRD patients on HD is unknown, but several mechanisms may be responsible including the presence of the $A-V$ fistula resulting in a left to right shunt with increased cardiac output and increased flow to the pulmonary circulation. Patients with PH appear to have higher fistula flow, lower EF, and the site of fistula as well as renal transplant status appear to impact flow and PASP respectively [18]. Manipulating fistula flow experimentally, however does not appear to impact PASP $[19,20]$. Compression of the AV fistula has been shown in some studies to lower CO and PASP, and PH may regress following renal transplant [21], although results have been inconsistent.

Anemia and volume overload in ESRD patients worsens these circulatory changes. In addition, endothelial dysfunction is common among ESRD patients. Decreased basal nitric oxide activity in uremic patients has been established, with multiple proposed mechanisms. Immediately following HD, there is a significant increase in circulating NO2 + NO3, though this is less pronounced in patients with $\mathrm{PH}$ [22]. Studies have shown increased levels of endothelin-1 (ET-1) in patients with ESRD, as well as decreased nitric oxide metabolites in some subsets of patients on HD via AV access [21]. Shear stress with vascular remodeling has also been proposed. Hormonal and metabolic derangements accompanying ESRD, including activation of the renin-angiotensin-aldosterone system and increased sympathetic tone lead to increased systemic and pulmonary pressures may also be implicated in vasoconstriction and increased pulmonary vascular resistance in $\mathrm{PH}$. Sub-clinical air microemboli, originating from tubing and the HD apparatus, have been detected by ultrasound during routine HD sessions both at the AV access site and in the carotid circulation [23], though the majority are carried to the pulmonary circulation [24]. Microbubbles are known to obstruct blood flow in capillary beds, resulting in tissue ischemia followed by an inflammatory response with platelet activation and aggregation with clot formation and activation of the complement cascade, and these processes may contribute to progressive endothelial damage and dysfunction at the capillary level with progressive obstruction and ensuing PH [25], after repeated exposures to HD and subclinical microemboli.

Extraosseous pulmonary calcification is commonly found in ESRD patients on HD [26], and may involve the interstitium of the alveolar septum, bronchial walls and walls of the pulmonary vessels, which may also be related to the pathogenesis of PH in this population [23]. Although extraosseous calcification is well described, correlation between pulmonary calcification and $\mathrm{PH}$ has not been obtained. There is also evidence for direct effect of the dialyzer membrane composition on PASP. The inverse relationship between ultrafiltered volume and post HD PASP has been correlated only with specific dialyzer membrane composition [27], and as such some patients will manifest high, fixed PASP independent of ultrafiltered volume, though the mechanisms for this remain unresolved.

Since initial reports describing pulmonary hypertension in long-term hemodialysis patients, increasing evidence has accumulated supporting the association between ESRD, HD and $\mathrm{PH}[28,29]$. Although there appears to be relatively high prevalence of $\mathrm{PH}$ among all ESRD patients, those on HD are more likely to be affected, with prevalence of pulmonary hypertension ranging from 17-56\%. The wide variations in prevalence estimates have been attributed to variable estimates of pulmonary artery pressure, ranging from $35 \mathrm{~mm}$ $\mathrm{Hg}$ to $45 \mathrm{~mm} \mathrm{Hg}$ derived by echocardiography. In addition, few studies have compared invasive to non-invasive measurements in the ESRD population on HD.

In our study, mean EF was well preserved (53.2\% $14.7 \%$ ) with higher estimates of PCWP using echocardiography. These findings suggest that diastolic heart failure with preserved systolic function may be the mechanism for clinical heart failure in a significant proportion of patients. Studies have shown that clinical heart failure occurs at an annual rate of $7 \%$, with nearly a third of HD patients having current or prior CHF at initiation of HD [30]. For the entire group in our study, the EF was lower in $\mathrm{PH}$ than in normal PASP patients with echocardiographic evidence of Grade I diastolic dysfunction, which is usually not associated with high PCWP. 
Analysis of our data using the current AHA/ACC guidelines for LVEF for classification of heart failure, that is, HFpEF and HFrEF, found significant differences between the two groups with respect to LV hypertrophy and size, diastolic dysfunction and PA pressure. The patients with HFrEF compared to those with HFpEF had more severe LV abnormalities, as well as PH. HFrEF patients compared to those with HFpEF had dilated $\mathrm{LV}$ with larger end diastolic and end systolic dimensions, and more severe LVH. LV diastolic dysfunction was consistent with moderate impairment (pseudonormalization or Grade II) in both HFrEF and HFpEF, with more severe impairment in HFrEF. HFpEF patients had moderate PH, whereas HFrEF had severe PH. Overall, our data show that HFpEF with moderate $\mathrm{PH}$ and mild abnormalities of LV structure and diastolic function occurs more frequently in ESRD. On the other hand, HFrEF is less common, but is associated with severe $\mathrm{PH}$, and more severe $\mathrm{LV}$ structural abnormalities.

Left ventricular structural abnormalities are common among patients with ESRD on HD. Grossly, these changes include LV dilatation and more commonly LV hypertrophy [31]. These structural alterations are accompanied by changes in the microvasculature with myocardial ischemia, and extraosseous calcification and fibrosis, microscopically $[32,33]$. Functional abnormalities ensue, with both systolic dysfunction and diastolic dysfunction [34-37]. Clinically, heart failure occurs at an annual rate of $7 \%$, with nearly a third of HD patients having current or prior CHF at initiation of HD [38]. Based on our data of more severe LV abnormalities and PH in patients with HFrEF vs. HFpEF, we believe ESRD patients with HFrEF are at a high risk of cardiovascular morbidity and mortality

Our study included patients with LV dysfunction (both systolic and diastolic) and did not exclude those with CAD of CHF. As such, our population is a representative "real world" sample of the HD patients at one center in the United States. The sample size is similar to that in extant studies. Further, we feel that our estimate of PASP 10-12 hours after completion of HD better represents the dry weight of HD patients at steady state, which is more likely to reflect real world loading conditions of the LV, in this hemodynamically complex patient population. Invasive studies have confirmed a high prevalence of $\mathrm{PH}$ among dyspneic patients (both those receiving and those not receiving dialysis), and have demonstrated that dialysis can unmask precapillary $\mathrm{PH}$ (defined as pulmonary arterial wedge pressure (PCWP) $\leq$ $15 \mathrm{~mm} \mathrm{Hg}$ ) in the presence of PH [39]. PASP was estimated per American Society of Echocardiography Guidelines [40], using the maximal TR jet velocity added to estimated right atrial pressure (RAP) derived from IVC dimensions, and thus attempted to include an estimation of the patient's actual volume status, contrary to prior studies which assigned an arbitrary number to right atrial pressure [6].

Several limitations may be identified within our study.
This was a single center trial with a small sample size. In addition, assessment of diastolic filling was done using trans-mitral velocities, a non-invasive and less than ideal estimation of PASP. Data suggest that tissue Doppler may have a role in evaluating diastolic function in HD patients above traditional Doppler measurements [41], but this modality was not available at our institution at the initiation of the study. Further, significant evidence exists showing tissue Doppler is not independent of preload in ESRD patients [41-44]. The optimal timing of TTE for hemodynamic assessment in ESRD is yet to be determined. Some studies have completed TTE immediately following dialysis (or 1-2 hours later) [45], though some have evaluated patients one day after completion of HD [45]. The relationship between the significant fluid shifts accompanying HD and timing of equilibration, plus the effects of chronic volume overloaded states remain areas of investigation. It is uncertain when best to asses HD patients, either non-invasively or invasively, as there are such large fluctuations in circulating blood volume and LV loading conditions. Finally, PH is common among HD patients and depressed LV systolic function may be important in the pathogenesis of PH in HD patients. However, ESRD and HD related changes are also likely mechanisms of depressed LV function contributing to $\mathrm{PH}$ in some degree and further research is needed to full understand this complex relationship.

\section{Acknowledgement}

\section{Disclosures}

Daniel B Levin, Umar I Malik, MD; Ihab Ajaaj; Jon P Blaschke, MD; Betty Skipper, PhD; Sandra L McClelland, RN; Kathleen Fagan, RDCS; Antonia M Harford, MD; Veena Raizada, MD; have no relationships relevant to the contents of this paper to disclose.

Philip G Zager is a DCI employee.

\section{References}

1. Simonneau G, Montani D, Celermajer DS, Denton CP, Gatzoulis MA, et al. Haemodynamic definitions and updated clinical classification of pulmonary hypertension. Eur Respir J. 2019; 53. 1801913. PubMed: https://www.ncbi.nlm.nih.gov/pubmed/30545968

2. Lam CSP, Roger VL, Rodeheffer RJ, Borlaug BA, Enders FT, et al. Pulmonary Hypertension in Heart Failure with Preserved Ejection Fraction: A Community-Based Study. J Am Coll Cardiol. 2009; 53: 1119-1126. PubMed: https://www.ncbi.nlm.nih.gov/pubmed/19324256

3. Carrasco-Sánchez FJ, Ortiz-López E, Galisteo-Almeda L, CamachoVázquez $\mathrm{C}$, Ruiz-Frutos $\mathrm{C}$, et al. [Prognostic importance of pulmonary hypertension in heart failure with preserved ejection fraction]. Rev Clin Esp. 2010; 210: 489-496.

PubMed: https://www.ncbi.nlm.nih.gov/pubmed/20855061

4. Abdelwhab S, Elshinnawy S. Pulmonary Hypertension in Chronic Renal Failure Patients. Am J Nephrol. 2008; 28: 990-997. PubMed: https://www.ncbi.nlm.nih.gov/pubmed/18635926

5. Zlotnick DM, Axelrod DA, Chobanian MC, Friedman S, Brown J, et al. Non-invasive detection of pulmonary hypertension prior to renal transplantation is a predictor of increased risk for early graft dysfunc- 
tion. Nephrol Dial Transplant. 2010; 25: 3090-3096.

PubMed: https://www.ncbi.nlm.nih.gov/pubmed/20299337

6. Yigla M, Fruchter $\mathrm{O}$, Aharonson D, Yanay N, Reisner SA, et al. Pulmonary hypertension is an independent predictor of mortality in hemodialysis patients. Kidney International. 2009; 75: 969-975. PubMed: https://www.ncbi.nlm.nih.gov/pubmed/19212417

7. Fathi R, Isbel N, Haluska B, Case C, Johnson DW, et al. Correlates of subclinical left ventricular dysfunction in ESRD. Am J Kidney Dis. 2003; 41: 1016-1025.

PubMed: https://www.ncbi.nlm.nih.gov/pubmed/12722036

8. Hung $\mathrm{KC}$, Lee $\mathrm{CH}$, Chen $\mathrm{CC}$, Chu $\mathrm{CM}$, Wang $\mathrm{CY}$, et al. Advanced left ventricular diastolic dysfunction in uremic patients with type 2 diabetes on maintenance hemodialysis. Circ J. 2012; 76: 2380-2385. PubMed: https://www.ncbi.nlm.nih.gov/pubmed/22786470

9. Janda S, Shahidi N, Gin K, Swiston J. Diagnostic accuracy of echocardiography for pulmonary hypertension: a systematic review and meta-analysis. Heart. 2011; 97: 612-622.

PubMed: https://www.ncbi.nlm.nih.gov/pubmed/21357375

10. Ganda A, Weiner SD, Chudasama NL, Valeri AM, Jadoon A, et al. Echocardiographic changes following hemodialysis initiation in patients with advanced chronic kidney disease and symptomatic heart failure with reduced ejection fraction. Clin Nephrol. 2012;77: 366-375. PubMed: https://www.ncbi.nlm.nih.gov/pubmed/22551882

11. Fabbian F, Cantelli S, Molino C, Pala M, Longhini C, et al. Pulmonary Hypertension in Dialysis Patients: A Cross-Sectional Italian Study, Pulmonary Hypertension in Dialysis Patients: A Cross-Sectional Italian Study. International Journal of Nephrology, International Journal of Nephrology. 2010; 2011: e283475.

PubMed: https://www.ncbi.nlm.nih.gov/pubmed/21151534

12. Ling Y, Johnson MK, Kiely DG, Condliffe R, Elliot CA, et al. Changing Demographics, Epidemiology, and Survival of Incident Pulmonary Arterial Hypertension. Am J Respir Crit Care Med. 2012; 186: 790-796. PubMed: https://www.ncbi.nlm.nih.gov/pubmed/22798320

13. Badesch DB, Raskob GE, Elliott CG, Krichman AM, Farber HW, et al. Pulmonary Arterial Hypertension: Baseline Characteristics From the REVEAL Registry. Chest. 2010; 137: 376-387.

PubMed: https://www.ncbi.nlm.nih.gov/pubmed/19837821

14. Thenappan T, Shah SJ, Gomberg-Maitland M, Collander B, Vallakati A, et al. Clinical Characteristics of Pulmonary Hypertension in Patients With Heart Failure and Preserved Ejection Fraction. Circ Heart Fail. 2011; 4: 257-265.

PubMed: https://www.ncbi.nlm.nih.gov/pubmed/21411741

15. Agarwal R. Prevalence, determinants and prognosis of pulmonary hypertension among hemodialysis patients. Nephrol Dial Transplant. 2012; 27: 3908-3914.

PubMed: https://www.ncbi.nlm.nih.gov/pubmed/22290987

16. Ramasubbu K, Deswal A, Herdejurgen C, Aguilar D, Frost AE. A prospective echocardiographic evaluation of pulmonary hypertension in chronic hemodialysis patients in the United States: prevalence and clinical significance. Int J Gen Med. 2010; 3: 279-286. PubMed: https://www.ncbi.nlm.nih.gov/pubmed/21042428

17. Rudski LG, Lai WW, Afilalo J, Hua L, Handschumacher MD, et al. Guidelines for the echocardiographic assessment of the right heart in adults: a report from the American Society of Echocardiography endorsed by the European Association of Echocardiography, a registered branch of the European Society of Cardiology, and the Canadian Society of Echocardiography. J Am Soc Echocardiogr. 2010; 23: 685-713. PubMed: https://www.ncbi.nlm.nih.gov/pubmed/20620859

18. Beigi AA, Sadeghi AM, Khosravi AR, Karami M, Masoudpour H. Effects of arteriovenous fistula on pulmonary hartery pressure and cardiac output in patients with chronic renal failure. J Vasc Acess. 2009; 10: 160-166. PubMed: https://www.ncbi.nlm.nih.gov/pubmed/19670168

19. Acarturk G, Albayrak R, Melek M, Yuksel S, Uslan I, et al. The relationship between arteriovenous fistula blood flow rate and pulmonary artery pressure in hemodialysis patients. Int Urol Nephrol. 2007; 40: 509-513. PubMed: https://www.ncbi.nlm.nih.gov/pubmed/17985208

20. Unal A, Tasdemir K, Oymak S, Duran M, Kocyigit I, et al. The long-term effects of arteriovenous fistula creation on the development of pulmonary hypertension in hemodialysis patients. Hemodial Int. 2010;14:398-402. PubMed: https://www.ncbi.nlm.nih.gov/pubmed/20854331

21. Yigla M, Abassi Z, Reisner S, Nakhoult F. Pulmonary hypertension in hemodialysis patients: an unrecognized threat. Semin Dial. 2006; 19 : 353-357.

PubMed: https://www.ncbi.nlm.nih.gov/pubmed/16970730

22. Abassi Z, Nakhoul F, Khankin E, Reisner SA, Yigla M. Pulmonary hypertension in chronic dialysis patients with arteriovenous fistula: pathogenesis and therapeutic perspective. Curr Opin Nephrol Hypertens. 2006; 15: 353-360.

PubMed: https://www.ncbi.nlm.nih.gov/pubmed/16775448

23. Forsberg U, Jonsson P, Stegmayr C, Stegmayr B. Microemboli. developed during hemodialysis, pass the lung barrier and may cause ischaemic lesions in organs such as the brain. Nephrol Dial Transplant. 2010; 25: 2691-2695.

PubMed: https://www.ncbi.nlm.nih.gov/pubmed/20305135

24. BarakM, Nakhoul F, KatzY.Pathophysiology and clinical implications of microbubblesduringhemodialysis. SemininDialysis. 2008;21:232-238. PubMed: https://www.ncbi.nlm.nih.gov/pubmed/18363602

25. Barak M, Yeshayahu K. Microbubbles: pathophysiology and clinical implications. Chest. 2005; 128: 2918-2932.

PubMed: https://www.ncbi.nlm.nih.gov/pubmed/16236969

26. Rajkovača Z, Kovačević $P$, Jakovljević B, Erić Z. Detection of pulmonary calcification in hemodialised patients by whole-body scintigraphy and the impact of the calcification to parameters of spirometry. Bosn J Basic Med Sci. 2010; 10: 303-306.

PubMed: https://www.ncbi.nlm.nih.gov/pubmed/21108612

27. Kiykim AA, Horoz M, Orozcan T, Yildiz I, Sari S, et al. Pulmonary hypertension in hemodialysis patients without arteriovenous fistula: the effect of dialyzer composition. Ren Fail. 2010; 32: 1148-1152. PubMed: https://www.ncbi.nlm.nih.gov/pubmed/20954973

28. Yigla M, Nakhoul F, Sabag A, Tov N, Gorevich B, et al. Pulmonary hypertension in patients with end-stage renal disease. Chest. 2003; 123 : 1577-1582.

PubMed: https://www.ncbi.nlm.nih.gov/pubmed/12740276

29. Tarass F, Benjelloun M, Medkouri G, Hachim K, Benghanem MG, et al. Doppler echocardiograph evaluation of pulmonary hypertension in patients undergoing hemodialysis. Hemodial Int. 2006; 10: 356-359. PubMed: https://www.ncbi.nlm.nih.gov/pubmed/17014511

30. Fathi R, Isbel N, Haluska B, Case C, Johnson DW, et al. Correlates of subclinical left ventricular dysfunction in ESRD. Am J Kidney Dis. 2003; 41: 1016-1025.

PubMed: https://www.ncbi.nlm.nih.gov/pubmed/12722036

31. Alpert MA. Cardiac performance and morphology in end-stage renal disease. Am J Med Sci. 2003; 325: 168-178.

PubMed: https://www.ncbi.nlm.nih.gov/pubmed/12695722

32. Sarnak MJ. Cardiovascular complications in chronic kidney disease. Am J Kidney Dis. 2003; 41 ( 5 suppl): 11-17.

PubMed: https://www.ncbi.nlm.nih.gov/pubmed/12776309 
33. Cheung AK, Sarnak MJ, Yan G, Berkoben M, Heyka R, et al. Cardiac diseases in maintenance hemodialysis patients: results of the HEMO Study. Kidney Int. 2004; 65: 2380-2389.

PubMed: https://www.ncbi.nlm.nih.gov/pubmed/15149351

34. Foley RN, Parfrey PS, Kent GM, Harnett JD, Murray DC, et al. Serial change in echocardiographic parameters and cardiac failure in end-stage renal disease. J Am Soc Nephrol. 2000; 11: 912-916. PubMed: https://www.ncbi.nlm.nih.gov/pubmed/10770969

35. Raizada V, Skipper B, Taylor RA, Luo W, Harford AA, et al. Left ventricular diastolic function in patients on hemodialysis. J Investig Med. 2010; 58: 791-795.

PubMed: https://www.ncbi.nlm.nih.gov/pubmed/20517163

36. Losi MA, Memoli B, Contaldi C, Barbati G, Del Prete M, et al. Myocardial fibrosis and diastolic dysfunction in patients on chronic haemodialysis. Nephrol Dial Transplant. 2010; 25: 1950-1954. PubMed: https://www.ncbi.nlm.nih.gov/pubmed/20075436

37. Kimura H, Takeda K, Tsuruya K, Mukai H, Muto Y, et al. Left ventricular mass index is an independent determinant of diastolic dysfunction in patients on chronic hemodialysis: a tissue Doppler imaging study. Nephron Clin Pract. 2011;117: c67-c73.

PubMed: https://www.ncbi.nlm.nih.gov/pubmed/20689327

38. Fathi R, Isbel N, Haluska B, Case C, Johnson DW, et al. Correlates of subclinical left ventricular dysfunction in ESRD. Am J Kidney Dis. 2003; 41: 1016-1025.

PubMed: https://www.ncbi.nlm.nih.gov/pubmed/12722036

39. Pabst S, Hammerstingl C, Hundt F, Gerhardt T, Grohé C, et al. Pulmonary hypertension in patients with chronic kidney disease on dialysis and without dialysis: results of the PEPPER-study. PLoS One. 2012; 7: e35310. PubMed: https://www.ncbi.nlm.nih.gov/pubmed/22530005
40. Rudski LG, Lai WW, Afilalo J, Hua L, Handschumacher MD, et al Guidelines for the echocardiographic assessment of the right heart in adults: a report from the American Society of Echocardiography endorsed by the European Association of Echocardiography, a registered branch of the European Society of Cardiology, and the Canadian Society of Echocardiography. J Am Soc Echocardiogr. 2010; 23: 685-713. PubMed: https://www.ncbi.nlm.nih.gov/pubmed/20620859

41. Hayashi SY, Rohani M, Lindholm B, Brodin LA, Lind B, et al. Left ventricular function in patients with chronic kidney disease evaluated by colour tissue Doppler velocity imaging. Nephrol Dial Transplant. 2006; 21: 125-132. PubMed: https://www.ncbi.nlm.nih.gov/pubmed/16221719

42. Lee TY, Kang PL, Hsaio SH, Lin SK, Mar GY, et al. Tissue Doppler velocity is not totally preload independent: a study in a uremic population after hemodialysis. Cardiology. 2007; 107: 415-421. PubMed:https://www.ncbi.nlm.nih.gov/pubmed/17310115

43. Drighil A, Madias JE, Mathewson JW, El Mosalami H, El Badaoui N, et al. Haemodialysis: effects of acute decrease in preload on tissue Doppler imaging indices of systolic and diastolic function of the left and right ventricles. Eur J Echocardiogr. 2008; $9: 530-535$. PubMed: https://www.ncbi.nlm.nih.gov/pubmed/18490307

44. Park CS, Kim YK, Song HC, Choi EJ, Ihm SH, et al. Effect of preload on left atrial function: evaluated by tissue Doppler and strain imaging. Eur Heart J Cardiovasc Imaging. 2012; 13: 938-947. PubMed: https://www.ncbi.nlm.nih.gov/pubmed/22514009

45. Fabbian F, Cantelli S, Molino C, Pala M, Longhini, Portaluppi F. Pulmonary hypertension in dialysis patients: a cross sectional Italian study. Int J Nephrol. 2010; 2011: 283475.

PubMed: https://www.ncbi.nlm.nih.gov/pubmed/21151534 